\title{
Public attitudes to wildlife and conservation in the Third World
}

\author{
A. H. Harcourt, H. Pennington and A. W. Weber
}

Conservationists in the West often assume that the people of the developing world are less concerned about wildlife than are people in the developed world. Recent surveys, in Tanzania, Brazil, Rwanda and the USA, have exploded this myth. The authors discuss the findings from these surveys and their implications for conservation. This paper was presented, in London in December 1985, at a symposiumCurrent Issues in Primate Conservationorganized jointly by the FFPS and the Primate Society of Great Britain.

Most people doing research in conservation are field biologists, who tend to work within wilderness areas. However, the threats to wildlife come predominantly from outside these areas, with the consequence that much conservation biology is in fact largely irrelevant to conservation. It might enable better avalanche fences to be built, but it does little to prevent the avalanche. One potential outside threat that wildlife faces is the public's attitude to it. Western conservationists and 'development' planners appear to assume that the Third World public is almost entirely antagonistic to conservation and ignorant of conservation issues. Recent surveys in Tanzania, Rwanda, Brazil and the USA show, on the contrary, that little difference exists between the countries, and thus indicate that there is as strong indigenous support for conservation in Third World countries as there is in the industrialized West.

The surveys in Tanzania, Rwanda and Brazil investigated attitudes to general conservation issues. The Tanzanian survey (Pennington, 1983 ) sampled 1217 primary and 800 secondary 152 school pupils. Because less than one per cent of the Tanzanian population attends secondary school, the results presented here concem mostly the primary school pupils. In Brazil 520 adults were interviewed (Kleiman et al., 1986). The Rwandan study consisted of two surveys, four years apart, of 72 and 119 farmers, respectively (Weber, 1981, 1986). The part of the survey in the USA described here concentrated on attitudes to coyotes and wolves (Kellert, 1985). Nevertheless, it is comparable to the other surveys because a strongly significant correlation existed between attitudes to the predators and attitudes to wildlife in general. Three-and-a-half thousand adults responded to the questionnaire in the USA.

The results are separated into three broad questions.

1. Should wildlife be protected?

2. If so, why?

3. What influences attitudes to wildlife?

\section{Should wildlife be protected?}

In the Tanzanian study (Pennington, 1983), about as many primary school pupils thought that national parks had a higher priority than other forms of land use as thought the reverse. Thus, in response to the statement 'If food were scarce, national parks should be used for farming', 39 per cent disagreed, compared with 45 per cent agreeing. In the Brazil study (Kleiman et al., 1986), 74 per cent of landowners said that they would protect or leave alone wildlife on their property. In Rwanda (Weber, 1981, 1986), 49 per cent of the earlier sample of farmers living adjacent to the National Park did not consider that the Park

Oryx Vol 20 No 3, July 1986 


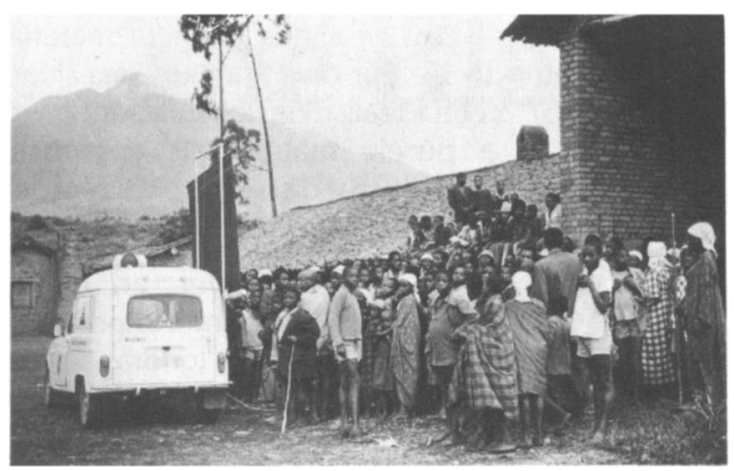

Setting up an audio-visual presentation; part of the conservation awareness programme in Rwanda ( $C$. and $R$. Aveling).

should be converted to agriculture. Finally, in the USA, 42 per cent of the general public liked wolves to some degree, and 39 per cent expressed varying levels of dislike (Kellert, 1985). Thus, all the surveys produced roughly the same result: about as many people expressed some form of support for wildlife and its protection as expressed disapproval.

\section{Why should wildlife be protected?}

In both Rwanda and Brazil, the conservation area adjacent to the sampled population was forest. In reply to questions concerning the utility of the protected forest, the majority of responses in both countries concerned the forest's impact on the climate (Weber, 1981, 1986; Kleiman et al., 1986). In Rwanda, a more specific question was asked of the farmers, 'Does the mountain forest have any effect on your water supply?' Half ( 49 per cent) of the earlier sample replied that it did.

Most Tanzanian national parks are savannah, and have no role in water catchment. In this country the most common response, 40 per cent, to questions about the role of the national parks was that they earned foreign exchange. A very similar response was given by Rwandan farmers in the first survey to questions concerning the utility of protected wildlife: 39 per cent saw tourism as its main value. In the Tanzanian study, responses could be separated into utilitarian and 'ethical' values. As well as providing such material benefits as foreign exchange and animal products, Tanzanian primary school pupils also saw national parks as existing to protect animals and Third World attitudes to conservation

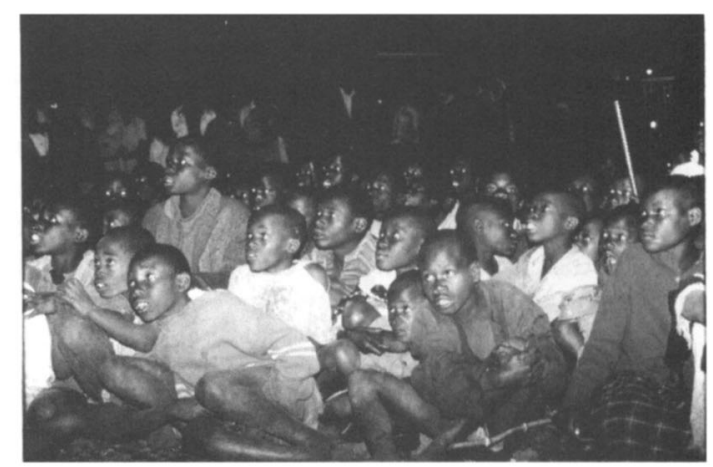

Audience at an audio-visual presentation near the Parc des Volcans, Rwanda (C. and R. Aveling).

to preserve Tanzania's heritage for future generations. Where a total of 53 per cent of responses were utilitarian, 37 per cent were 'ethical'.

\section{Influences on attitudes to wildlife}

Several different influences correlate with attitudes to wildlife. Knowledge of wildlife is one of them. In both the USA and Tanzanian studies, people with less knowledge showed significantly less support. Thus, within the primary school population in Tanzania (Pennington, 1983), 44 per cent of pupils with low scores for knowledge of wildlife thought that national parks should be used for agriculture compared to 24 per cent of those with high scores; and while 42 per cent of low-knowledge pupils thought that national parks should be discontinued if tourists ceased to visit them, only 18 per cent of high-knowledge ones thought this. Similarly, in the USA (Kellert, 1985), the median low-knowledge respondent 'disliked' wolves (score of -2 on a seven-point 'like to dislike' scale), whereas the median high-knowledge respondent 'liked' them (score of +2 ).

The data so far show only correlations, not cause and effect. However, in Rwanda (Weber, 1981, 1986) surveys of farmers' attitudes were conducted in the first and fifth years of a conservation awareness campaign in the country. Over the four-year period, a marked improvement in attitudes was apparent, which is difficult to attribute to anything other than the campaign itself. The proportion of local farmers who saw some utility in the protected forest rose from 49 per cent to 81 per cent; the proportion who saw utility in the

153 
protected wildlife rose from 41 per cent to 63 per cent; the proportion who saw the forest as beneficial to the water supply to their fields rose from 49 per cent to 86 per cent; and the proportion who thought that the national park should be converted to agriculture dropped from 51 per cent to just 18 per cent. All changes were highly significant statistically.

\section{Implications for conservation}

The results surveyed here show that public attitudes in Third World countries differ little, if at all, from attitudes in the industrialized West. The optimistic conservationist can thus find substantial public support for his work. In Rwanda in 1984, for example, over three-quarters of the farmers adjacent to the national park stated that they did not want the Government to make the park available to them for cultivation. Conservationists need to make use of this support, both in promoting their own ideals and in opposing externally imposed development programmes. At present they do not. Instead of integrating the needs and wishes of the local people into the programmes, they concentrate on punitive policing of the conservation areas. The inevitable outcome is exacerbation of existing conflict and eventual defeat in the face of an expanding antagonistic population. Yet a conservation programme that can elicit support will undoubtedly be more successful than one opposed by it. More than that, it might even be able to help the local people resist the sorts of externally funded 'development' programmes that constitute one of the most destructive forces in the Third World at present.

The roles that Rwandans ascribed to a protected conservation area were almost entirely utilitarian, and in Tanzania also, materialistic justifications predominated. Nevertheless, in Tanzania a strong moral basis was additionally apparent. In the words of one Tanzanian secondary school pupil, '. . . from the beginning of the world there were animals. They deserve to be protected because they also deserve the right to live. They are creatures just as human beings are.' Of course, such idealism is not in itself sufficient to save wilderness. In a country in which half the population is not interested in wildlife or national 154 parks, the park that provides tangible material profit is going to be the one that survives (Harcourt, 1986). Yet if idealism is not sufficient on its own, nor is a purely materialistic approach. Material profits can always dry up; ethical reasons for conservation are more enduring.

At the end of the day, however, an empty stomach and a sick child are more powerful arguments than a moral principle. Ignorance and lack of interest are certainly responsible for some destruction of wildlife. In other areas, greed plays a major role (Myers, 1984; Caufield, 1985). But over much of the world, wilderness is invaded neither for pleasure, nor for profit, but out of necessity (e.g. Sai, 1984). Only by removing the necessity can the wilderness be saved.

\section{Acknowledgment}

We thank Kelly J. Stewart for comments.

\section{References}

Caufield. C. 1985. In the Rainforest. W. Heinemann Ltd, London.

Harcourt, A.H. 1986. Gorilla conservation: anatomy of a campaign. In Primates: The Road to Self-Sustaining Populations (Eds K. Benirshke and D. Lindburg). SpringerVerlag, New York (in press).

Kellert, S.R. 1985. Public perceptions of predators, particularly the wolf and coyote. Biological Conservation, 31, $167-189$

Kleiman, D., Beck, B.B., Dietz, J.M., Dietz. L.A., Ballou, J.D. and Coimbra-Filho, A.F. 1986. Preparation of golden lion tamarins for reintroduction to the wild. In Primates: The Road to Self-Sustaining Populations (Eds K. Benirshke and D. Lindburg). Springer-Verlag, New York (in press)

Myers, N. 1984. The Primary Source. W. W. Norton \& Co., London.

Pennington, H. 1983. A living trust: Tanzanian attitudes towards wildlife and conservation. M.Sc. Thesis. Yale University, New Haven.

Sai, F.T. 1984. The population factor in Africa's development dilemma. Science. 226, 801-805.

Weber, A.W. 1981. Conservation of the Virunga gorillas: a socio-economic perspective on habitat and wildlife preservation in Rwanda. M.Sc. Thesis. University of Wisconsin, Madison.

Weber, A.W. 1986. Socioecological factors in the conservation of afromontane forest reserves. In Primate Conservation in Tropical Rain Forest (Eds J.S. Gartlan, C.W. Marsh, and R.A. Mittermeier). Alan R. Liss, New York (in press).

A. H. Harcourt, Department of Applied Biology. University of Cambridge. Pembroke Street, Cambridge CB2 3DX. UK.

H. Pennington, 96 Blake Street. New Haven. Connecticut. USA.

A.W. Weber. USAID, BP 28. Kigali, Rwanda

Oryx Vol 20 No 3, July 1986 